Profesora titular en la Universidad de Salerno, donde alterna cursos y publicaciones de Literatura Española contempóranea con otros de Literatura Hispanoamericana. Es autora de numerosos ensayos y monogralias publicados en Italia, Francia, España y Uruguay sobre la literatura de la guerra civil española y del exilio (las revistas «Hora de España» y «Romance», Juan Gil Albert, Ro-

\title{
EL NUEVO DESCUBRIMIENTO DE LOS EXILIADOS ESPAÑOLES EN AMÉRICA*
}

\author{
ROSA MARIA GRILLO
}

sa Chacel, José Bergamín, Max Aub etc.), sobre géneros literarios (cuento, autobiografía, epistolario), autores españoles e hispanoamericanos (Mario Benedetti, Horacio Quiroga, José Pedro Díaz, Fernán Caballero, Rosa Montero etc.) y sobre la narrativa hispanoamericana del ‘900 (realismo mágico, novela histórica posmoderna etc.)

Hay momentos en la historia poscolonial española en que América, por diferentes motivos, se vuelve tema recurrente de investigaciones científicas y de creación literaria ${ }^{1}$ : en el 900 sin duda pensamos en el 'nuevo descubrimiento' que protagonizaron los republicanos españoles exiliados en América, y, en las últimas décadas, en el notable afán de comprensión y reinterpretación motivado por la conmemoración del V Centenario.

Si aceptamos la teoría de José Gaos de las dos patrias, la de origen y la de destino -la que nos ha tocado en suerte y la que hemos elegido, aunque se trate de una elección forzada, impuesta por las circunstancias - en la que podemos llegar a sentirnos transterrados ${ }^{2}$ y no desterrados y con la que se instaura una peculiar afinidad espiritual ${ }^{3}$, entonces podemos leer algunas de las obras de tema americano de los exiliados como el fruto de un cuestionamiento del destino español -castizo, imperial, católico-y de la asunción del destino americano, con todo lo que conlleva la relectura de la historia del Descubrimiento y de la Conquista. Escribe Gaos: «España es la única colonia que permanece colonia de sí misma, la única nación hispano-americana que del común pasado imperial, queda por hacerse independiente, no sólo espiritual, sino también políticamente [...] Aceptamos como destino, que pronto reconocimos como bienvenido, la América en que podíamos prolongar sin defección la tradición del liberalismo español, que reconocíamos ser la tradición triunfante en la independencia de estos países y en sus regímenes liberales» ${ }^{4}$. También para Sender es posible tener dos patrias y nutrir para las dos los mismos sentimientos: «Yo no me siento

extranjero. Soy un mexicano más y a veces blasfemo contra México y otras lo adoro hasta un extremo para el cual no hay palabras adecuadas. Lo mismo pasaba con mi patria España. Todos hijos de la chingada, pero compartiendo el mismo destino, no sé cuál ni me importa» ${ }^{5}$. Sin duda en México este fenómeno fue más evidente, sea por el alto número de intelectuales exiliados que dejaron su testimonio en este sentido, que porque el México posrevolucionario de los años ' 30 , a pesar de evidentes renuncias y ajustes, parecía más próximo a las espectativas de los exiliados y por lo tanto favoreció su americanización. Este sentimiento de patria dual parece ser confirmado por las palabras y las obras de autores como Max Aub, Ramón J. Sender, José Moreno Villa, Enrique Díez Canedo, José María Camps ${ }^{6}$, y muchos más que han hecho de México y de su historia tema no ocasional de sus obras de creación y de reflexión, ya que los exiliados fueron 'conquistados' por el nuevo mundo y en su proyecto político cabía la desmitificación de la España Oficial, de 1939 como de 1492.

Aunque ya exista una amplia bibliografía sobre los textos de tema americano escritos por los exiliados ${ }^{7}$, me parece oportuno anali-

Agradezco la amabilididad de Donatella Pini, Paco Tovar y Teresa Ferriz que me han proporcionado algunos de los textos analizados.

1

Luis Cernuda en su ensayo Variaciones sobre un tema mexicano (México, Porrúa, 1952) señala cómo los hechos de América han despertado siem- pre escaso interés entre los escritores $\mathrm{e}$ intelectuales peninsulares, mientras que José Luis Abellán señala que en el primer tercio del siglo XIX hubo un buen número de autores liberales que escribieron sobre las guerras de independencia ( $" \mathrm{Fi}$ losofía y pensamiento: su función en el exilio de 1939», en El exilio español de 1939, III, Madrid, Taurus, 1976, pp. 189-190). Tampoco podemos olvidar la atención de los escrito res del ' 98 hacia el 'desastre' $y$ su condena de la España imperialista.

2

Juan Ramón Jiménez al llegar a Buenos Aires después de siete años de exilio en Estados Unidos habló de conterrados.

3

Cfr. José Luis Abellán, «El exilio de 1939: la actitud existencial del transterrado", en AA.W., El exilio cultural de la guerra civil (19361939), Ediciones Universidad de Salamanca, 2001, pp. 19-27.

4

Ángel Gaos, cit. por Abellán, ibid., p. 26.

5

Ramón J. Sender, Nocturno de los catorce, Barcelona, Destino, 1970, p. 31.

6

Cfr. por ejemplo Miguel Cabañas Bravo, "México me va creciendo. El exilio de José Moreno Villa», en AA.W., El exilio literario, I, Barcelona, GEXEL-Cop d'Idees, 1998, pp. 211-227, y Josep Mengual Català, «El teatro mexicano de José María Camps», ibid., Il, pp. 481-489

7

Valga recordar el libro de Marielena Zelaya Kolker, Testimonios americanos de los escritores españoles transterrados de 1939, Madrid, Instituto de Cooperación Iberoamericana, 1985.

El nuevo descubrimiento de los exiliados españoles en América ROSA MARIA GRILLO 


\section{8}

Cfr., entre otros muchos títulos AA. W., Historia y novela, Poitiers, CNRS, 1996; AA.W., La novela histórica, núm. monogr. de Cuadernos de Cuadernos, México, n.l, 1991; AA.WV., Histoire et lmaginaire dans le roman hispano-américain contemporain, núm. monogr. de América, París, n. 12, 1993, y n. 14, 1994; Santiago Juan-Navarro, La metaficción historiográfica en el contexto de la teoría postmodernista, Valencia, Episteme, 1998; AA.W., Discurso historiográfico y discurso ficcional, núm. monogr. de Río de la Plata, París, n. 11-12, 1991.

9

R. González Echevarría, "García Márquez y la voz de Bolívar», en Cuadernos de Cuadernos, cit., p. 63.

10

Podemos citar a Salvador de Madariaga llas cinco novelas de Esquiveles y Manriques: El corazón de piedra verde, Guerra en la sangre, Una gota de tiempo, El semental negro, Satanael), Francisco Ayala (El hechizado), José María Camps (El gran Tianguis), Jesús de Galíndez (Cinco leyendas del trópico), y un largo etcétera.

\section{1}

Cfr. Rosa Maria Grillo, «La visione dei vinti nel romanzo storico latinoamericano», en Annali dell'Istituto di Studi Latinoamericani, n. 4, 2001, en prensa, y «La otra Historia: parodia y desacralización del Descubrimiento en la narrativa hispanoamericana», en Actas del XXIII Congreso de Americanística, Perugia, mayo 2001 , en prensa.

12

Cfr. José Antonio Pérez Bowie, "La historia como ficción en Las máscaras del héroe de J.M. de Prada», en España Contemporánea, n. 2, 1988, pp. 61-72.

13

Eugenio F. Granell, La novela del Indio Tupinamba, Madrid, Fundamentos, 1982, p. 127.

El nuevo descubrimiento de los exiliados españoles en América

ROSA MARIA GRILLO zar un campo fecundo y cargado de significado como la ficción histórica, tanto narrativa como teatral, centrada en aquel primer encuentro entre Europa y América, que de forma privilegiada se presta a múltiples interpretaciones y sobre todo a la de los vencedores y a la de los vencidos. Además la fecha del V Centenario ha desencadenado una serie de polémicas y revisiones históricas y filológicas (descubrimiento, encubrimiento, invención, choque, encuentro, desencuentro, etc.), y en las últimas décadas nuevas teorías históricas y antropológicas (la Nouvelle bistoire francesa, el pensamiento deconstruccionista y revisionista, la atención y el respecto hacia la otredad) han favorecido una operación cultural y política que tiende a deconstruir y reconstruir la Historia y su sentido - principio de causaefecto, linealidad y fragmentariedad, univocidad y pluralidad, inversión de la relación Yoel Otro, Historia e historia de la mentalidad, de tradiciones y costumbres, etc.

A la luz de estas 'conquistas' nosotros, los lectores del siglo XXI, podemos leer aquellas obras como antecedentes, como obras pioneras de la novela histórica posmoderna ${ }^{8}$, que quiere precisamente deconstruir la Historia Oficial y re-escribirla según otros códigos y perspectivas. Naturalmente en esta operación no podemos olvidar que estamos cumpliendo un análisis basado sobre un anacronismo crítico, aunque esté justificado por la singularidad de la experiencia de aquellos escritores exiliados a Latinoamérica que se americanizaron y asumieron la visión de los vencidos, ya que ellos mismos eran los vencidos de aquella misma España del Imperio y de la Inquisición. En efecto, lo que Roberto González Echevarría ha escrito refiriéndose a la situación latinoamericana actual, bien se corresponde con la situación de los exiliados en 1939: «los textos coloniales poseen el hechizo del origen, de un principio que no ha dejado de serlo porque las cuestiones que engendró siguen todavía vigentes en América Latina. Re-escribir esos textos equivale a narrar tanto un presente cargado de urgencias como un pasado que no deja de ser actual»?.

Muchas serían las novelas históricas que podrían ser útiles a nuestro análisis ${ }^{10}$, pero hemos elegido dos textos muy singulares - que sólo ampliando enormemente el ámbito de la novela histórica en sentido posmoderno podemos llamar así (ya que son parodias, histo- rias virtuales, inverosímiles en el nivel factual pero cargadas de profundo significado en el nivel político e historiográfico, que se desarrollan en un marco histórico bien definido)y cuatro obras de un autor, Ramón J. Sender, que sin alejarse lo más mínimo de la estricta referencialidad, cumple una sutil revisión del sentido de la Historia: modalidades y tonos diferentes para evidenciar la misma disconformidad respecto a la Historia Oficial.

En el primer caso, tenemos dos ejemplos evidentes de inversión total del punto de vista: la Conquista, España y los españoles, contados por aborígenes americanos.

Eugenio F. Granell en La novela del Indio Tupinamba (1959) unifica los dos episodios que hemos indicado como ejes de nuestro análisis - la Conquista y la Guerra Civil-en una novela surrealista y disparatada, con continuos cambios geográficos y temporales y con protagonistas arquetípicos: el Conquistador, el Indio, el Cura, el Intelectual, el Gitano, el Académico, el General etc. Sorprendentemente moderna, esta novela parece inspirarse al mismo tiempo en un concepto cíclico de la historia, de raíz indígena, y en la imagen de una España inmóvil, arraigada en su tradición clerical e imperialista. Para conseguir estos fines, Granell utiliza aquellos recursos 'destabilizzanti'11 o desrealizadores y rupturistas ${ }^{12}$ que caracterizan la nueva novela histórica: la coincidencia o superposición de tiempos diversos, la ironía, la escritura extrañada y paródica, la inversión de roles, los anacronismos, la invención desaforada pero de profundo significado crítico etc. No faltan tampoco los recursos típicamente surrealistas como la enumeración caótica («También le sería rehusado [el carnet] al que fuera sacrílego, eunuco, esquizofrénico, morfinómano, cazador furtivo, ateo, tuberculoso, contrabandista, proxeneta, comunista, fascista, mongol, crupier, paria, güelfo, apatrida, monárquico, espía, hugonote, asesino, anarquista, plagiario, cosaco, etrusco, prófugo, bígamo, carbonario, terrorista, nazista, dentista, dietista, modista, centurión, apestado, cuatrero, adventista del séptimo día, apuntador, galeote, mormín y bosquimano»13) y metáforas arriesgadas, crueles y poéticas al mismo tiempo ( En esa quebradura del formidable espejo humano que aquel día era la Sierra Camellera se quebraron todos los reflejos. Quedaron cortadas las imágenes por múltiples aristas de cartón festo- 
neadas de sangre. Cada partícula de algo, de paisaje o de objeto, de visión o de carne, quedó clavada en una punta de vidrio. Un cataclismo de astillas fue aquello. Como lluvia de espejos partidos o algo así. Ya no se sabía si lo rojo de la sangre era lo rojo de la sangre, del fuego o del crepúsculo. Los espejos rojos opacaban los tronantes ámbitos transformados en millones de minúsculas piezas puntiagudas de rompecabeza colosal», (pp. 116-117). Las palabras de María Teresa González de Garay a propósito de El Indio... bien podrían referirse a muchas de las novelas históricas hispanoamericanas contemporáneas, por ejemplo a las de Abel Posse, Augusto Roa Bastos o Alejandro Paternáin: «La modernidad y originalidad de este humor surrealista son notables. La modernidad se percibe en el peculiar estilo, reiterativo y lleno de argumentaciones disparatadas, a pesar de la lógica que encierran, tanto desde el punto de vista sintáctico como semántico y fonético [...] Granell es muy barroco cuando se divierte en este peculiar uso de las repeticiones y los rodeos sobre el mismo tema» ${ }^{14}$. Igualmente moderna es la escritura extrañada, utilizada por ejemplo para indicar, sin utilizar el nombre correspondiente, una extensión de chabolas que, desde arriba y desde lejos, parece un panorama singular y cautivador: «Se asomaron por el lugar indicado y convinieron ambos [el Indio y el Cura] que era una vista, verdaderamente, de las más hermosas. Hasta el horizonte se componía un ameno paisaje de tejados de cinc, restallante de amarillos, azules y rojos, de envases de marcas de galletas y pastas para sopas. En las cajas de madera y de cartón de otros productos vibraban colorines. El ingenio nativo había logrado, con tan parcos materiales, construir una extensa y complicada red de viviendas» (p. 186).

El Indio Tupinamba, improbable dueño de una librería en la España de la Guerra Civil, «con el trasero al aire [...] y con una rueda de plumas de ave coloreadas puesta en la cabeza» (p. 16), entra inmediatamente en conflicto con los representantes de la España oficial: con un Señor, «que era nada menos que todo un Conquistador español de los de América [que] se dedicó a cortarle la cabeza al Indio Tupinamba, poniendo en su empeño mucho afán. Después se la ponía otra vez, para inmediatamente proceder a cortársela nuevamente, y así por el estilo, hasta que se la cortó y se la puso mu- chísimas veces» (pp. 16-17), y con un Cura, con quien no hay posibilidad de comunicación ya que sus diálogos ejemplifican el eterno tema de la incomunicabilidad entre riberas distantes y nos hacen sonreir no por la ingenuidad de la visión del Indio, candorosa pero lógica en su ignorancia', sino por la suponencia de universalidad que encierra el discurso del Cura: «Preguntó el Indio Tupinamba que quién era ése al que llamaban Cristo. A lo que el Cura repuso: 'Es el padre de todos'. $\mathrm{Y}$ el Indio Tupinamba concluyó: 'Entonces, ¿̇es España su harem?’ (p. 19).

No podemos leer estas líneas sin pensar, naturalmente, en los múltiples episodios en los que los conquistadores, basándose en la supuesta universalidad de su idioma y de su religión, acusaron a los indios de impíos y blasfemos, mientras que la ingenua pregunta del Indio Tupinamba nos hace reflexionar sobre la naturaleza simbólica de nuestros códigos civiles y religiosos: fuera de nuestra cultura, nuestros ritos y nuestros símbolos son tan incongruentes como los ritos indígenas para los conquistadores españoles. Si bien representante de un 'pueblo joven', y por lo tanto primordial e incivil según cierto pensamiento eurocéntrico, el Indio, cuando no comprende el comportamento del General, con mucha sabiduría piensa que «tal vez se tratase de algún ritual característico de la cultura de occidente» (p. 40). Y esto es el nuevo 'descubrimiento' que han hecho los narradores posmodernos, sobre todo hispanoamericanos: resaltar, eso es 'descubrir', los mecanismos eurocéntricos que han regido el discurso historiográfico y las novelas históricas tradicionales, románticas o realistas, construidos ambos por los vencedores, y proponer otro 'descubrimiento' - encuentro, desencuentro, choque- desde el punto de vista del 'otro'. En una de las últimas páginas, Granell indica una de las modalidades para re-escribir esa Historia, una de las muchas hechas propias por la poética posmoderna: «El Indio Tupinamba pensó en un conjuro. Aquello era un conjuro. El mendigo era una lagartija. Aquella lagartija era una profecía. La profecía, un sueño. El sueño confundía el ayer y hoy, aquí y allá, esto y aquello. La confusión ponía una rica corona de plumas al recuerdo. La corona
14 María Teresa González de Garay, «El clavo en la narrativa de Eugenio F. Granell», en El exilio literario español de 1939, II, cit., p. 127.
El nuevo descubrimiento de los exiliados españoles en América ROSA MARIA GRILLO 
15

Piénsese en García Márquez que en El otoño del Patriarca presenta los mismos elementos, pero al revés, es decir vistos por los indigenas.

16

Recordemos que había sido el Conquistador quien había cortado la cabeza al Indio y luego la había puesto otra vez en su lugar.

17

Existe una traducción al castellano, autorizada por el autor, de la cual cito: Palabras de Opoton el viejo. Crónica del siglo XVI de la expedición azteca a España, Barcelona, Ediciones 29, 1977. El texto comprende una Introducción en que el autor, un pintor $y$ escriłor español que vive en México, revela haber encontrado un "manuscrito con nuestra grafía del siglo dieciséis, pero redactado en náhuatl» (p. 19) que está ahora en el Museo de Culturas Prehispánicas. Varias notas referenciales y una larga lista de "fuentes de comprobación de datos», desde Bernardino de Sahagún hasta Miguel León Portilla, hacen una lectura de tipo casi pragmática (es decir, la de las novelas históricas tradicionales según la terminologia de K Stierle en «¿Qué significa 'recepción' en los textos de ficción??», en AA.W., Estética de la recepción, Madrid, Arco, 1987, pp. 87-1431.

18

La descripción de esas canoas - tan diferentes de las que usaban normalmente- y de las galeras españolas son ejemplos magníficos de 'escritura extrañada' y de ingenua correspondencia entre el nombre y la cosa: «Lo mismo podía ser una casa que cualquier otra cosa extraña, todo menos una canoa. Pero me consta que sí lo era y además Cuauchichic me lo diijo y me lo aseguró desde el primer momento") ( $p$. 30); "Las galeras dichas naves son como una imitación de nuestras canoas, pero más redondas por fuera, pues ellos tienen maderas curvadas que nunca se han visto en el Aztlán [...] No tienen remos, pero el viento las mueve cuando hay viento. Llevan mantas grandes y gruesas, di-

El nuevo descubrimiento de los exiliados españoles en América ROSA MARIA GRILLO de plumas tocaba la campana» (p. 209). Confundir 'el ayer y hoy, aquí y allá, esto y aquello' significa proponer la coincidencia entre Conquista, Guerra Civil, ese 'nuevo descubrimiento' y el moderno imperialismo económico y cultural occidental, y utilizar en sentido paródico y anacrónico los textos canónicos de la historiografía oficial, por ejemplo el famoso paso de Colón sobre el primer encuentro con los indios americanos, su generosidad en cambiar oro por vidrio colorado, su desnudez, sus caras pintadas etc., paso utilizado repetidas veces por los escritores hispanoamericanos $^{15}$. Narrando la llegada de los españoles exiliados a la República Occidental del Carajá, Granell escribe: «El Obispo se apresuró a comprar una cosa de cada. La venta se generalizó. Se cambiaron productos por monedas, por promesas, por puro gusto» (p. 133). Pero Granell va más lejos cuando se anticipa -de nuevo por boca del Indio- a afirmaciones científicas muy recientes: «Son muchos los errores de la historia. Y por si hubiera pocos, aún quieren aumentarlos», siempre, naturalmente, sin tener en cuenta la visión de los vencidos: "Ahora existe un clan de historiadores empeñados en demostrar que América fue descubierta por los Vikingos» (p. 44).

Como se puede notar, no se trata de un puro juego surrealista, o de una serie de inventos pirotécnicos de gran efecto, sino de un empeño muy moderno por restablecer la verdad —otra verdad - con un sentido crítico muy fuerte, "poniendo una nota de humorismo en el justo centro del horror» (p. 46); un humorismo negro, generalmente, que juega con las palabras, alternando el significado referencial con el metafórico y el positivo con el negativo, el nivel trágico con el cómico etc. Tragicómico es, por ejemplo, el episodio del fusilamiento del Indio, de su esposa gitana y su padre (todos ellos víctimas de la política integralista española): «Se oyó una descarga, pero los tres condenados ni siquiera se movieron. Era porque en vez de tener la cabeza puesta

chas velas, $y$ el viento las hincha $y$ las hace caminar [...] y como van atadas a la galera, la galera se va detrás del viento» (p. 135). Estas descripciones, y la idea misma de la novela, se pueden comparar con la Crónica del descubrimiento (Montevideo, Banda Oriental, 1980) del uruguayo Alejandro sobre los hombros, como es lo corriente, la habían puesto los tres, tan campantes, debajo del brazo derecho ${ }^{16}$. Se les ocurrió recurrir a esta ingeniosa estratagema al percatarse, por la voz de mando del jefe del pelotón, de que les iban a apuntar a la cabeza. El jefe ordenó a sus criados que disparasen de nuevo, pero esta vez apuntando al lugar por donde las cabezas aparecían sonrientes, como asomadas a la ventana triangular formada por el brazo derecho doblado contra la cadera» (p. 92).

Se podría seguir con muchos ejemplos más de ingeniosas invenciones que evidencian el deseo de Granell de mirar a la Conquista y a la Guerra Civil con el mismo ojo: el de los vencidos, de entonces y de ahora, ya que se siente él mismo parte de aquel mundo hispánico derrotado una y otra vez y que seguía vivo a pesar de las victorias, viejas y nuevas, de la España Oficial. Pero Granell no ahorra críticas tampoco a sus compañeros, poniéndose una vez más como autor incómodo y transgresivo: los intelectuales adeptos a la poesía popular (pp. 23-24, 33-36), los comunistas burócratas defensores de la marcada gerarquización del Partido (pp. 25-26), los refugiados, retratados irónicamente en sus posturas más radicales, como cuando hablan sin interrupción de España en tertulias y círculos y siguen escribiendo cartas, manifiestos y peticiones (pp. 175-177).

Del mismo tono es también Paraules d'Opoton el Vell ${ }^{17}$ (1968) de Avel.lí Artís-Gener, exiliado en México desde 1940 hasta 1965, que sólo al volver a España publica esta novela contracorriente: es la relación que Opoton, alfarero azteca, escribe a los «veinte veces cuatro años» (p. 23) para luchar contra el olvido, «porque nuestra raza azteca se está perdiendo y quiero que quede memoria de cuando nuestra pujanza era tan grande [...] y si lo cuento con todo detalle es porque de esas cosas ya sé que apenas guardáis memoria porque todo se nos ha deshecho hundido reventado derribado $y$ todos andáis demasiado atareados entre cirios, incienso y agua bendita» (pp. 45-46). La escritura está motivada también por la singularidad de su experiencia: el viaje con 3.700 compañeros en seis canoas gigantes - con una «escalera que también estaba abajo, según fueras subiendo o bajando ya que, de otro modo, no la llamaríamos escalera" y una "especie de casa»18 (p. 31) - construida para navegar hacia el Levante para ir «a buscar al buen Dios Quetzalcóatl, cuyo retorno, según los oráculos, ya era 
imminente» (p. 42). Si bien no encuentran a Quetzalcóatl, 'descubren' una tierra lejana y desconocida, Galecia, en el Viejo Aztlán ${ }^{19}$, con una costa «tan rota que debería darles vergüenza» (p. 164), donde se les toma por fieles de Sant Yago y se les empuja a hacer el peregrinaje a Santiago, después de ser señalados como infieles, y son derrotados: de los 3.700 que partieron desde el Gran Tenochtitlan, regresan sólo 17, convencidos de que «el susodicho Sol Naciente está siempre más allá [...] nunca te acercas a él, porque él se va más allá a medida que tú te acercas [...] no es un lugar, sino un símbolo» (p. 196). Y al escribir su relación, muchos años más tarde, cuando ya los españoles han 'descubierto' América y derribado al imperio azteca, Opoton tiene también otra convicción: «Nosotros les enseñamos el camino y aquí los tenemos, y ya no podremos echarlos nunca más, pues por experiencia sé cómo es de tozuda la Raza Castilla, la cual ya no suelta jamás lo que ha arramblado» (p. 196).

Este libro es una summa de los topoi del Descubrimiento, vistos por supuesto al revés, con evidente intención desmitificadora y crítica de la relatividad y parcialidad de la perspectiva europea. Artís-Gener usa los mismos recursos de los cronistas españoles -neologismos, escritura 'extrañada', asimilación del léxico indígena, comparación de lo nuevo con lo ya conocido- para presentar la otra cara de los fundamentos de la cultura occidental católica que guiaron la conquista. Ejemplar es el caso de 'bárbaro' y 'pagano' que son términos, y conceptos, absolutamente relativos, nacidos como pareja opositora a otro término, y concepto, y que en el tiempo han adquirido un sentido absoluto y negativo: «nos llamaron bárbaros, que es un gran insulto, a causa de nuestros sacrificios, pero en el Viejo Aztlán vimos cosas peores y nunca les llamamos bárbaros» (p. 51). Más adelante, asistiendo a una función del Santo Oficio, se preguntan si se trata de sacrificios humanos: «Preguntamos qué era aquello y solamente nos dijeron apostasía y pensamos que sería alguna gran fiesta con hogueras y macehualitzli. Pero después vimos que apostasía era como una enfermedad, pues compadecían a los apóstatas como a gente condenada [...] Los ataron cada uno a su palo y los sacerdotes venga a decir cosas en el nahuatlatoli de ellos, el susodicho latín, y después encendieron la leña y quemaron a toda la apostasía encapuchada y era como sacrificio a los Dioses pero los sacrificados no estaban contentos de serlo» (p. 163). Todo el proceso histórico subsiguiente al viaje de Colón está aquí sometido a revisión, la misma revisión llevada a cabo por la revolución crítica e ideológica de las ciencias humanas de la posmodernidad y anticipada por Avel.lí Artís-Gener, gracias a su doble destino, ya en los años '50: «Pero tengo que decir que nos servimos de malas palabras desde el primer momento, pues he puesto descubrir y en verdad lo dijimos muchas veces y era fea palabra, porque descubrir quiere decir quitar la cobertura de aquello que uno encuentra tapado, y el Viejo Aztlán no estaba tapado y si no hubiéramos ido tan atolondrados, el sentido común nos habría dictado la palabra justa, que habría sido encuentro, porque nada estaba tapado y a ver de dónde sacamos eso de descubrir» (p. 69). Al Descubrimiento sigue la Conquista («nuestro viaje, en mala hora dicho Conquista», p. 84) con la afirmación unilateral de posesión («-Ahora mismo, en este momento, os declaréis vasallos de Nuestro Gran Señor Aquel Que Habla [...] No os estoy consultando, no os propongo ninguna cosa que vosotros podáis decidir [...] Os doy una orden en nombre de Nuestro Gran Señor Aquel Que Habla y vosotros, gente galega del Viejo Aztlán, no podéis hacer otra cosa sino obedecer», p. 91) y el primer Requerimiento ( $\mathrm{Al}$ día siguiente por la mañana tomamos posesión de la tierra en nombre de Nuestro Gran Señor Aquel Que Habla y fue una ceremonia sencilla pero llena de reverencia [...] Hicimos una estatua de Nuestro Dios Encaminador y la dejamos puesta en la playa, como señal de que habíamos estado allí y habíamos tomado posesión de aquella tierra en nombre del Nuevo Aztlán, que éste es el verdadero nombre de tierra de aztecas [...] Yo creo que es preciso que quede puesto en el papel ya que de otro modo mi historia quedaría fallida, que eso de tomar posesión de la tierra no teníamos que haberlo hecho porque no era nuestra ni íbamos a ganar tierras, sino a recibir a Quetzalcóatl y nada más», (p. 78). Regresado Opoton a su tierra, sufre la llegada y la Conquista española, de la cual casi no habla quizás para no caer en los topoi de la violencia y de la crueldad; en cambio analiza la tentativa por parte de «los sacerdotes extranjeros buenos» que habían seguido a los primeros conquistadores, de recuperar parte de la cultura que habían
«Decíamos que el Viejo Aztlán era el más viejo de los Aztlanes, o sea, de donde Él [Quetzalcóatl] había venido. Y ese Primer Lugar era el que nosotros buscábamos» (pp. 83-84).
El nuevo descubrimiento de los exiliados españoles en América

ROSA MARIA GRILLO 
aniquilado: «nos preguntaban muchas cosas de nuestro náhuatl y no hace muchos días [...] aún me llamaron a Tlatelolco y me hicieron cantar la canción de los guerreros del Aztlán [...] Ahora que ya lo han destruido todo es cuando lo quieren remendar. Y pocos años atrás todo estaba bien entero y ahora vienen a que les cuentes cómo hacíamos un bautizo o qué le decíamos a Coatlícue cuando le pedíamos una buena cosecha. Y cuesta trabajo entender que quieran saber esas cosas, cuando ya han cortado la cabeza a todos los Coatlícues» (p. 162).

Si en estos párrafos se cuestiona toda la historia de la relación entre España y América, 'descubriendo' realidades que la historiografía había borrado o silenciado, no faltan tampoco descripciones e interpretaciones risueñas y livianas que, en el fondo, siempre contienen también un sinsentido, una violencia contra la naturaleza, algo que sólo el conocimiento del código correspondiente puede justificar: desde la preparación del queso (muy artificial porque «se quita [a cabras o vacas] la leche que tendría que ser para los recién nacidos», p. 99) al tipo de calendario o al uso de vestidos y monedas ( Te dan las cosas a cambio de los redondelitos, y a eso le dicen comprar y vender, pero me quedé sin saber dónde compran los susodichos redondelitos», p. 122).

El libro termina con un «mensaje de Opoton a Nuestro Huey Tlatoani Ahuízotl» (p. 193), casi un testamento de Avel.lí-Opoton quienes, después de haber conocido esto y aquello, protagonistas ambos de 'descubrimientos' muy peculiares y de derrotas que les han obligado a mirar con nuevos ojos a sus propias culturas y a sus propias Historias, la europea y la americana, apelan a la comprensión y al respeto hacia la otredad: "Yo creo que sólo hay un Dios Grande y Verdadero, pero no todo el mundo lo llama Quetzalcóatl. En otras tierras le dan un nombre diferente y por lo visto la lista de nombres es muy larga. Yo digo como pregunta que cómo podría haber Dioses diversos que hubieran emprendido el mismo trabajo de hacer el mundo, los hombres, la Mar y los árboles [...] El hombre, $\mathrm{Pa}$ dre Mío Venerado, es egoísta de nacimiento y cree que sólo su representación del Dios es la buena y las ajenas las considera como ídolos, que es la forma que han inventado, envidiosa y despectiva, de hablar de las imágenes del Dios hecha por los demás» (p. 196). Si esta aptitud etnocentrista es evidente en materia de religión, Opoton la descubre también en otros aspectos de la Conquista y su juicio es, si es posible, aún más tajante: «Como vieron que no leíamos ni escribíamos como ellos [...] creían que no sabíamos llevar la cuenta de nuestras Garbas, ni el registro de nuestra historia de aztecas tenochcas. Ellos no entendieron como en nuestros papeles se contaba todo y los quemaron de la misma manera que queman a la gente viva, pues adivinaron que aquélla era nuestra historia viva» (p. 196). Todo esto que queda explicitado en este 'mensaje', casi un ensayo de moderna etnoantropología, en el texto está ilustrado y concretizado en mil anécdotas y aventuras, contadas con el tono liviano e irónico de un Gulliver del siglo XVI que ha vivido y conocido, además, la teoría de la relatividad y la crisis del optimismo burgués de nuestro siglo.

No hay en este libro ningún invento surrealista, no hay ni cabezas cortadas ni superposición de tiempos y espacios diferentes como en la novela de Granell: antihistórico es sólo el planteamiento inicial, el viaje desde Occidente hacia el Levante, lo demás es totalmente verosímil (la parte ficcional) y referencial (el cuadro histórico y geográfico), distorsionado, eso sí, por la óptica «al revés volteada» como escribe el autor en la sobrecubierta. Quién podría no reconocer, por ejemplo, a los Reyes Católicos en esta definición: «También tenían a un Gran Señor Aquel Que Habla, a su manera, claro, y él tenía una Gran Señora, eso es, Aquella Que Habla, cosa la cual quiere decir que hablaban los dos [...] y yo diría que es por este motivo por lo que les cuesta entenderse, pues es costumbre bárbara. Entonces, cuando nosotros llegamos, los Nuestros Grandes Señores de ellos estaban muy atareados, pues tenían una gran guerra contra unas tribus forasteras que se habían establecido en aquellas tierras hacía ya dieciseis Garbas de las nuestras y señoreaban una buena parte de la tierra y nunca pudimos saber si aquellas tribus eran gentes de Quetzalcóatl, pues las expulsaron antes de que nosotros pudiéramos tener trato con ellas» (pp. 86-87). Son ellos, sin duda, Fernando e Isabel, pero como disfrazados, mirados a través de un vidrio deformante que es el de la diferencia de culturas, de la 'otredad' que tantas veces nos ha impedido ver y entender, y al contrario nos ha empujado a encubrir y a no descubrir. 
Y podemos afirmar que no es por azar que Artís-Gener haya escrito este texto al volver a España $\mathrm{a}^{20}$ : ha tenido que 'reconocer' y reconquistar a su España, mirarla con los 'ojos vírgenes' de Opoton, de un vencido que quiere comprender lo sucedido y dejar memoria de su paso por el mundo, antes de que la versión de los vencedores borre definitivamente su huella y su memoria.

Menos llamativa es sin duda la inversión que opera Ramón J. Sender en sus obras de tema americano ya que no se aleja nunca de la estricta referencialidad ni utiliza técnicas desrealizadoras o rupturistas como la parodia y la escritura extrañada; además, sus protagonistas pertenecen a la Historia ${ }^{21}$, lo que generalmente deja espacios más restringidos a la creatividad ficcional. Sender, que ha hecho de España, de sus contradicciones, de su historia, tema diríamos único de sus obras, encuentra en México y en el sur de Estados Unidos nuevos pretextos para hablar de España, pero siempre elevando al hombre y las circunstancias españolas a dimensión universal, retratándolos en una condición extrema: «No busco una verdad útil... ni siquiera esa inofensiva verdad estética siempre falsa y artificiosa busco la verdad humana»22. A Sender, que se documentaba y. estudiaba detalladamente las fuentes, le interesaban, más que la exactitud de la anécdota, los individuos, personajes históricos que adquieren la función simbólica de representar la condición perenne del hombre y de su «rebelión metafísica contra el mundo» ${ }^{23}$ y contra la injusta opresión.

En los casos que vamos a analizar, una verdad humana que no puede prescindir de la historia de las relaciones entre América y España, que según Sender fue «desde el principio una relación no tangencial, como fue la de los ingleses u otros imperios coloniales, sino intersticial de sangre y convivencia» ${ }^{24}$.

Ya se había acercado a temas americanos cuando nada dejaba vislumbrar todavía su largo exilio en aquellas tierras (los textos ensayísticos El problema religioso en México, 1928, La América antes de Colón, 1928) pero es con su estancia en Guatemala, México y en el sur de Estados Unidos que su interés fragua en obras importantes de tema americano ${ }^{25}$ y de enfoque trágicomítico, reforzado por lo que Soldevila llama «curiosidad por las 'ciencias ocultas' [...] y un creciente interés por el ocultismo y por el problema de la sobrevi- da» ${ }^{26}$. Responden fundamentalmente a estas preocupaciones los nueve cuentos sobre el pasado legendario azteca de Mexitayotl (1940), y La cisterna de Chichén-Itzá (1981), fábula moderna ambientada en Yucatán, casi un pretexto para describir ritos y mitos indígenas y confrontarlos con los europeos y orientales. En la misma línea se sitúan Los tontos de la Concepción (1963), ambientado en las misiones franciscanas en Arizona en el siglo XVIII, y Novelas ejemplares de Cíbola (1961), constituido por doce cuentos, algunos reescritos a partir de los de Mexitayotl, otros nacidos de una atenta lectura de Bernardino de Sahagún y que revelan una forma de sincretismo profundo entre las religiones indígenas y la cristiana, $y$ en fin algunos que, a pesar de estar ambientados en época moderna, denotan la supervivencia de cosmogonías precolombinas. Otras obras se refieren a la realidad contemporánea: El bandido adolescente (1965), Epitalamio del Prieto Trinidad (1942), Relatos fronterizos (1972), Nocturno de los catorce (1969), Tanit (1970).

Recreaciones pormenorizadas de ambientes y sucesos de la conquista y colonización españolas son en cambio Hernán Cortés (1940), Jubileo en el zócalo (1964), La aventura equinoccial de Lope de Aguirre (1964), Tupac Amaru (1973). Siempre con miras a restablecer la verdad y a impugnar la Historia Oficial, a demostrar el peligro presente en cualquier visión maniquea y preconcebida de la Historia, esta época le ofrece personajes que, por haberse encontrado en situaciones extremas, han asumido el rol de héroes trágicos, más allá de connotaciones étnicas, nacionalistas etc.: Tupac Amaru, Lope de Aguirre, Cortés, Xhinotecatl y Moctezuma responden a estos requisitos y además constituyen nudos ambiguos y susceptibles de múltiples interpretaciones historiográficas que permiten a Sender, una vez asumido su doble destino, español y americano, buscar nuevas verdades buceando entre documentos, tradiciones, leyendas y relatos de diversa procedencia.

Sender elige como protagonistas de estas obras a hombres fuertes, fuera de la ley o al margen de ella, cuya compleja psicología y contradicciones intenta rescatar: personajes en los que Sender sin duda refleja su índole anárquica e impulsiva y en cuyas aventuras quiere desdibujar su visión del mundo, desilusionada y consciente de la imposibilidad de deslin-
20

«Fue un libro de difícil y lento gestación: ¡łardé trece años en escribirlo! Bueno, sin exageración: en pensarlo, escribirlo, reescribirlo, estudiar una geografía ignorada y aprender un bellísimo idioma. Ésta que el lector tiene en sus manos es la tercera versión: las dos anteriores no resistieron exámenes posteriores》 (sobrecubierta). Por lo tanto podemos deducir que Artís-Gener, si bien ha ideado y empezado la novela en México, escribió la versión definitiva estando ya en España.

21

Generalmente las novelas históricas contemporáneas se insertan en la línea trazada por Walter Scott (personajes ficticios dentro de un marco histórico) mientras que en la literatura latinoamericana abundan casos de protagonistas históricos (según el esquema de Alfred de Vigny) 'revisitados' por la óptica posmoderna como el Colón de El arpa y la sombra de Alejo Carpentier o el Lope de Aguirre de Daimon de Abel Posse.

22

Ramón J. Sender, Siete domingos rojos, Barcelona, Balagué, 1932, p. 5 .

23

Francisco Carrasquer, Imán y la novela histórica de Sender, London, Thamesis Books, 1970, p. 186.

24

Ramón J. Sender, Ensayos del otro mundo, Barcelona, Destino, 1970, p. 77.

25

Marielena Zelaya Kolker contabiliza 13 obras de tema americano (del Norte y del Sur, ya que Sender a partir de 1942 vivió en el suroeste de Estados Unidos, tierra de substrato mayaespañol, por lo que su exilio en tierra anglófona no significó nunca un total apartarse del mundo hispánico). No incluye en su lista La cisterna de Chichén-lizá e incluye los Ensayos del otro mundo (1970).

26

Ignacio Soldevila Durante, La novela desde 1936, Madrid, Alhambra, 1980, p. 71.

El nuevo descubrimiento de los exiliados españoles en América ROSA MARIA GRILLO 
Ramón J. Sender, «Antes de comenzar», en Tupac Amaru, Barcelona, Destino, 1973, p. 9.

\section{8}

La novela, sin añadir nada al perfil literario de Sender, evidencia en el paratexto ("Antes de empezar» y "Prólogo que el lector se puede saltary) y en el texto (en la proliferación documental que sin duda le quita calidad literaria, y en algunos párrafos metanarrativos) los mecanismos de creación que han permitido la escritura de las obras más significativas en este campo, La aventura equinoccial de Lope de Aguirre y Jubileo en el zócalo: «Hay dos clases de verdades: las que suceden en la vida y las que se sueñan. Estas últimas son las verdades de los poetas [...]; un día un hombre letrado y con buena relórica escribirá algo sobre lo que estamos haciendo ahora. $Y$ añadirá y quitará sucesos según las reglas del arte. Así, pues, todo será al mismo tiempo verdad y mentira, según como se mire» (Ramón J. Sender, Tupac Amaru, cit., p. 181).

\section{9}

Cuando Sender escribe esta novela ya el movimiento uruguayo de los tupamaros era un hecho concreto y en el «Prólogo que el lector se puede saltar» se pregunta si hay realmente correspondencia entre los dos movimientos. No podemos descartar que ésta, como toda novela histórica, esté escrita con la mirada hacia el pasado así como hacia el presente, y que Sender quiera también subrayar la distancia y las diferencias que median entre la realidad histórica, el mito y su utilización por parte de los revolucionarios uruguayos.

\section{0}

A Enriquillo, el exiliado Jesús de Galíndez, dedicó una de sus Leyendas del trópico, «El Bohoruco».

31

Cfr. mi «La veridica storia di Lope de Aguirre dalle cronache al cinema», en Actas del Congreso Literatura y cine en América Latina (Napoli-Pagani-Salerno 1999), Caracas, La Casa de BeIlo (en prensa).

32

Ramón J. Sender, Proclamación de la sonrisa, Madrid, Juan Pueyo, 1934, p. 166.

El nuevo descubrimiento de los exiliados españoles en América

ROSA MARIA GRILLO dar netamente el bien y el mal, la verdad y la mentira, las leyes y sus infracciones.

Consciente de la imposibilidad de afirmar una sola verdad, Sender en "Antes de comenzar» ${ }^{27}$, una declaración de poética que acompaña Tupac Amaru'28, se propone desmitificar falsas verdades: "Yo he creído siempre que, aparte otras razones de orden estético, lírico, cultural, o de simple entretenimiento y amenidad, la razón que justifica sobre todo esta tarea de escribir (en estos turbios tiempos) es la necesidad de definir el mal y hacerlo patente en las conciencias de todos [...] Pero naturalmente con la verdad. Una de las peores raíces del mal está en la proclamación y divulgación de falsas verdades. Es decir, en la creación de mitos malignos capaces de confundir las mentes y descarriarnos a todos en nuestra conducta de cada día. Uno de esos mitos es nuestro idealismo de colonizadores» (p. 10). En el caso específico de Tupac Amaru, el autor confiesa: «Yo tuve siempre una gran simpatía, admiración y piedad natural por José Gabriel Tupac Amaru que sublevándose creía cumplir la voluntad de los Consejos de Indias. Ésta, era su dosis de ingenuidad y de sencilla nobleza que hay en todos los hombres superiores [...] Tupac Amaru está llamado a ser el mito indigenista de los países americanos de habla española» (p. 10).

Es decir, a través de la historia de un hombre, por algunos elevado a los altares del mito $^{29} \mathrm{y}$ por otros demonizado con las estigmas de la crueldad y de la traición, Sender quiere volver a escribir esa Historia resaltando todos los matices y las cualidades humanas del héroe, sus ingenuidades y sus frustraciones frente a la arrogancia y a las distorsiones o deformaciones del Poder: es posible hacerlo profundizando en sus sentimientos y pensamientos, confrontando toda la documentación posible, de ambos bandos («sucedieron algunas cosas importantes. O nimias, según se mire», p. 42), $\mathrm{y}$, licencia del relato ficcional, asumiendo el punto de vista del mismo Tupac Amaru como forma de compensación al largo silencio al que lo ha obligado la Historia Oficial.

Al contrario de lo afirmado por la Historia Oficial, el Tupac Amaru senderiano sigue siendo, hasta la muerte, fiel a su rey y a su religión: «Esta orden no es contra Dios, ni contra el Rey, sino contra las malas administraciones» (p. 14). En este registro se desarrolla toda la historia que permite la total rehabilita- ción de Tupac Amaru como hombre valiente, religioso y coherente, y permite a Sender lanzar sus ataques a ministros, sacerdotes, gobernadores, corregidores que traicionaban la voluntad del Rey y sus leyes ("las leyes de Indias eran comprensivas y humanitarias», p. 18). Restablecer la verdad y la justicia era la voluntad de Tupac Amaru, así como lo era de Guaman Poma de Ayala al escribir su Nueva Corónica y Buen Gobierno y lo era de Enriquillo, el cacique indio de Haití que guió la rebelión de su gente contra los colonizadores confiando en el apoyo de la corona ${ }^{30}$. Lo es también de Sender, que confirma su escéptica postura delante de la ley que, aunque buena, siempre sirve a quien gobierna para sobornar y explotar al pobre: si ingenuamente Tupac Amaru podía creer que sus quejas podían llegar y ser escuchadas por el Consejo de Indias, Sender insinúa la existencia de un frente compacto constituido por todos los representantes del poder, tanto en España como en las colonias.

Éste es el punto de arranque también de la historia de Lope de Aguirre, otro personaje incómodo de la historiografía española de la Conquista, señalado por muchos intelectuales hispanoamericanos, junto con Tupac Amaru, como un precursor de la Independencia: otro caso de revisionismo histórico, iniciado ya con Bolívar, y novelado en obras como Daimon de Abel Posse, Lope de Aguirre Principe de la libertad de Miguel Otero Silva, El camino de El Dorado de Arturo Uslar Pietri ${ }^{31}$. Junto a los hispanoamericanos, no faltan escritores españoles, desde Valle-Inclán a Sanchis Sinisterra que, con diversas motivaciones, lo eligen de protagonista de sus obras. El mismo Sender ya antes de la guerra civil había leído el libro de Emiliano Jos sobre Lope de Aguirre y en Proclamación de la sonrisa le había dedicado unas líneas en el apartado «Libertadores de América»: «Como primer mártir de la libertad de América, Lope de Aguirre está por descubrir y rehabilitar» 32

Este 'descubrimiento', en el ámbito más amplio del nuevo descubrimiento de América, lo intenta Sender en La aventura equinoccial de Lope de Aguirre, en donde quiere subrayar la empresa individual de un hombre tan ambiguo que puede ser llamado loco y traidor en las crónicas de sus compañeros, y príncipe de la libertad, béroe de la Independencia latinoamericana en la narrativa posterior. 
No existiendo documentos que puedan desmentir las acusaciones contenidas en las crónicas de Vázquez ${ }^{33}$ y de los demás marañones que, para defenderse a sí mismos, tuvieron que acusar a Aguirre de toda locura y traición, y no queriendo alejarse de la referencialidad histórica, Sender pone su atención más que en connotaciones ideológicas y políticas, en la caracterización psico-patológica del hombre, profundamente condicionada por su vida anterior y por los sucesos de la expedición: lúcido y loco, histrión y solitario, demagogo y tirano, tierno con su hija Elvira y despiadado con sus presuntos enemigos, calculador y colérico. Y, sobre todo, resentido y ambicioso: «el [resentimiento] de Lope lo era contra los hombres todos, contra el cielo y la tierra, contra el Rey y contra Dios. Los otros se daban cuenta de que algo fatídico y sombrío dominaba en la voluntad de Lope, pero no sabían qué. Ya no llamaban a Aguirre el loco porque veían que no era la razón lo que le faltaba, sino todo lo demás. Le faltaba todo en el mundo menos la razón. Y él quería apoderarse, con su razón, de todo lo que le faltaba ${ }^{34}$. Delante de la parcialidad de la Historia, Sender ha dado a su personaje la oportunidad de defenderse ${ }^{35}$ en un escrito autobiográfico incluido en La aventura..., en que Aguirre se confiesa y recuerda las injusticias sufridas: pero, para no contradecir la Historia que no nos ha legado ningún texto autobiográfico del tirano, en la novela él mismo lo «arrojó al fuego» (p. 63). Sender muestra así una realidad articulada, lejana del maniqueísmo que rige tanto la versión de la historiografía oficial como la de los escritores latinoamericanos que han querido hacer de Aguirre un príncipe de la libertad: una verdad humana según la cual el Aguirre senderiano es en parte la consecuencia de los mecanismos sociales de la España del 500 y de la Conquista.

Y para resaltar más esa 'verdad humana', le pone al lado un deuteroprotagonista, Pedrarias de Almesto, su confidente y conciencia crítica, hombre justo y leal, que intenta hasta el final ser su amigo sin abjurar de su fidelidad al rey: «Creo en la amistad y morir por ella es tan bueno como morir por el rey y aún mejor» (p. 237). Los de Aguirre y Pedrarias son diálogos que desmienten la imagen, que aparece en otros textos de ficción, de Aguirre héroe solitario y autosuficiente: lo que Aguirre busca en Pedrarias es el diálogo, la oposición constructiva, y no la adulación y la sumisión. De igual manera, Pedrarias pierde la connotación de hombre ambiguo, pronto a huir pero también a aceptar el perdón de Aguirre, y adquiere la de 'intelectual' de la jornada, no sólo porque viene utilizado como escribano sino porque es capaz de razonar por abstracciones, presagiar acontecimientos futuros, confrontarse con el pasado: dos hombres destinados a enfrentarse en el acto final, pero sin nunca llegar a ser símbolos maniqueos uno del Bien, otro del Mal.

Y para rehabilitar al personaje Lope de Aguirre, verdadero monstruo para la historiografía oficial española, Sender pone en relieve, como en Tupac Amaru, las justas causas de la rebelión primera de Aguirre, no en contra de la Corona, sino en contra de sus representantes, ineptos, ávidos, insensibles a los pedidos y espectativas de los soldados y prontos a satisfacer sus más bajos instintos: la codicia, la pasión, la envidia. Esto, sin cambiar la Historia, es suficiente para justificar en parte la rebelión de Aguirre contra Pedro de Ursúa y Fernando de Guzmán en nombre de la dignidad humana y en nombre de la masa que no tiene voz: de hecho, como Tupac Amaru, Lope de Aguirre se revela primero contra la conducta negativa y cruel de los representantes del Poder español en América, y sólo en una segunda etapa su rebelión se radicaliza y extiende contra el Poder mismo, tan lejano y extraño que no puede intervenir eficazmente en las cosas de América, hasta proclamarse Emperador de las tierras conquistadas (de aquí parte la posibilidad de indicarlo como primer rebelde americano).

Lo que sugiere Sender, sin querer borrar de la Historia los crímenes de Aguirre, es que sus rebeliones nacen de justas motivaciones históricas antes que individuales: Pedro de Ursúa era uno de esos hombres de «presencia provocadora que suscitan antagonismos [y que] afrontaba las dificultades con valentía y arrogancia» (p. 53), y había obtenido el nombramiento de jefe de la expedición por haber sometido a los indios chitareros y a los negros cimarrones con crueldad y astucia; además la presencia de su amante Inés de Atienza lo aleja «de cualquier interés por la humanidad entera» y por la misma jornada, y «este sentimiento, en un jefe, podía ser peligroso» (p. 57). Paralelamente a la descalificación de Ursúa, Sender insinúa una nobleza interior de
33

Muy poco sabemos de Aguirre que no sea lo que nos consignan las crónicas escritas por los marañones para defenderse de las acusaciones de haber apoyado al tirano en su rebelión. La más conocida es la Jornada de Omagua y Dorado de Francisco Vásquez.

34

Ramón J. Sender, La aventura equinoccial de Lope de Aguirre, s.c., Magisterio Casals, 1998, pp. 113-114.

35

La misma oportunidad que ha dado a Tupac Amaru, asumiendo en el texto su punto de vista y dándole la palabra en numerosos monólogos interiores.
El nuevo descubrimiento de los exiliados españoles en América ROSA MARIA GRILLO 
Ramón J. Sender, Nota preliminar a Jubileo en el Zócalo, Barcelona, Destino, 1974, p. 10.

\section{7}

Xinotecatl (1826) es la primera novela histórica latinoamericana, anónima, probablemente de un autor mexicano.

38

Ramón J. Sender, Monte Ondina, Zaragoza, Guara, 1989, p. 83 De Bernal Díaz del Castillo Sender aprecia también las descripciones de la naturaleza de México y de sus aborígenes (cfr. Ensayos del otro mundo, Barcelona, Destino, 1970, p. 65 y passim).

\section{9}

Jubileo en el zócalo se puede considerar tanto una novela como una obra de teatro: los 'capítulos' comprenden escenas dialogadas entre los 'espectadores', fácilmente representables, los diálogos del retablo, indicaciones escenográficas $y$, a veces, voces 'fuori campo', recurso éste último utilizado por Sender también en Hernán Cortés, por ejemplo en la recitación de romances y cantos indios. Cfr. José Carlos Mainer, "La narrativa de Ramón J. Sender: la tentación escénica», Bulletin Hispanique, n. $3-4,1983$, pp. $325-343$

El nuevo descubrimiento de los exiliados españoles en América ROSA MARIA GRILLO
Aguirre: su valentía (fue herido en dos ocasiones) que se convierte en rencor por no ser reconocida por los altos mandos, su lealtad a la Corona y su precoz defensa de los derechos de los indígenas ( las regulaciones sobre los indios eran bien pensadas, pero imposibles de practicar, como se vio después», p. 62). En fin, lo elige como «uno de esos héroes de la antiepopeya [que] moriría también tragado por una alimaña» (p. 67). Ni Pedro de Ursúa es 'buen señor' traicionado por su 'vasallo', ni éste último es loco y traidor sin tener sus buenas razones: es éste el mensaje revisionista que, sobre la Jornada de El Dorado, da Sender, investigando, como siempre lo hace, en esas 'verdades humanas' que dan sentido universal a sus personajes, pero dando al mismo tiempo una versión de la jornada, y de toda la Conquista y el Imperio español, crítica y demoledora.

Además Sender escinde su personaje en una confrontación a nivel social y político (Aguirre-Ursúa) y a nivel humano (AguirrePedrarias): Aguirre y Ursúa representan dos clases sociales que se enfrentan, el primero para afirmar sus derechos y vengarse de la mala suerte y las injusticias sufridas hasta entonces; el segundo para defender su estatus y el valor de un sistema político en que cree. Ya desde las primeras páginas, en la confrontación entre Aguirre y Ursúa éste último parece destinado a sucumbir bajo el influjo maligno de la «tarumba del equinoccio» (p. 85) y de Inés, hecho que Aguirre no puede perdonar en un jefe, y a la progresiva degeneración de Ursúa corresponde el progresivo engrandecimiento de Aguirre. La aventura equinoccial... se inscribe por lo tanto en la misma línea de las otras obras de tema americano de Sender: por un lado, mostrar el Bien y el Mal presentes en un mismo individuo, epopeya y antiepopeya; por otro, volver a escribir la historia mostrando otras posibles versiones y motivaciones de las acciones humanas y las luces y las sombras de la empresa española, sin aceptar nunca acríticamente ni la versión del vencido — silenciado por la Historia y rehabilitado por los escritores americanos- ni la del vencedor, Ursúa, vencedor en cuanto representante de España, cuya personalidad y acciones vienen magnificadas por los cronistas.

En cambio, Aguirre y Pedrarias son dos hombres que se respetan recíprocamente, a quienes Sender da iguales posibilidades de representarse en la narración y cautivar al lector; son dos hombres cabales, como lo son Cortés y Xhinotecatl en Hernán Cortés y en Jubileo en el Zócalo: «He escrito estas páginas libre de prejuicios, especialmente del prejuicio patriótico español o mexicano que no sería del caso y que no harían sino dificultar la objetividad. Confieso que sería difícil determinar si admiro más a Cortés o a los héroes que defendían a su patria contra el invasor» ${ }^{36}$.

Cortés y Xhinotecat ${ }^{37}$ son los protagonistas de dos textos escritos a más de veinte años de distancia: entre los dos media un mayor conocimiento de México y la lectura pormenorizada de La bistoria verdadera de la conquista de Nueva España de Bernal Díaz del Castillo, «fuente a la que me gusta acudir precisamente por saber que es sospechosa a los eruditos» ${ }^{38}$.

Gracias a lo que pudo leer en La bistoria verdadera... sobre las grandes fiestas que los indios celebraron en 1535 en el Zócalo, lo que en 1940 había sido sólo una obra de teatro escrita sobre la figura de Cortés en instancias de un actor español refugiado (Hernán Cortés), en 1964 llega a ser una obra compleja, teatro dentro del teatro o novela escénica, con Cortés y sus fieles que asisten a la puesta en escena, por parte de los indios, de un retablo sobre la conquista. La obra representada no es otra cosa que el drama senderiano Hernán Cortés con pequeños pero no insignificantes cambios que conciernen una mayor profundización en las costumbres y cosmogonías indias y en la figura de Xhinotecatl, del cual se resalta mayormente la entereza y el valor. $\mathrm{El}$ rol que Sender confiere a Bernal Díaz del Castillo - y a su versión no oficial de la conquista de México- es fundamental en esta revisión: en una nota preliminar reconoce esta deuda; en el capítulo primero ${ }^{39}$ copia unos párrafos de su libro; Bernal es actor que se mueve libremente entre los dos niveles de representación; finalmente, es objeto de muchos diálogos entre Cortés, Pedro de Alvarado, Sandoval, Narváez y el padre Bartolomé que lo consideran autor («trujimán») de la pieza y de todas las tergiversaciones y cambios respecto a la versión oficial de las Relaciones de Cortés. Hay por lo tanto una asimilación entre Sender, autor del Hernán Cortés del 40, y Bernal Díaz del Castillo, indicado como autor de la pieza representada. Esta superposi- 
ción entre los dos autores - que es a la vez desdoblamiento del único autor de las dos obras - se repite en la superposición-, desdoblamiento entre Cortés y los suyos que comentan y juzgan (nivel 1) los hechos representados (nivel 2) de los cuales ellos mismos son protagonistas. Son estas interconexiones precisamente las que permiten a Sender presentar con más esmero las posibles versiones de los acontecimientos, resaltando su problematicidad.

La última escena de Hernán Cortés en la que los protagonistas de la conquista, vivos y muertos, se mezclan y discuten sobre los acontecimientos, representa el germen de la obra sucesiva: «el desdoblamiento escénico de las conciencias [que] patentiza la profunda ambigüedad de toda ¿verdad?, hecha siempre de culpas inquietantes, de inocencias culpables, de crueldades necesarias» ${ }^{40}$. No sólo esta misma escena vuelve, ampliada, en Jubileo..., sino que a partir de aquí empieza el proceso de mise en abîme que se va a repetir hasta el infinito y se concluirá en una procesión que es representación por antonomasia ${ }^{41}$ : «En el retablo los actores repiten las palabras de Cortés y también las de Alvarado exactamente, improvisando. Entonces se da cuenta Cortés de que en el escenario está reproducida la sala no como en un espejo sino como es la sala misma, incluido el escenario y el retablo, es decir que en el fondo del escenario hay otro retablo igual donde se reproduce de nuevo la sala y en el fondo del segundo retablo el tercero y así cada vez más lejos hasta el infinito como en un larguísimo túnel» (Jubileo..., pp. 198-199).

Por lo tanto, en Jubileo, con respecto a Hernán Cortés, hay una visión múltiple tanto a nivel extradiegético como intradiegético: Sender vuelve a escribir la misma obra y juzga la Historia después de 20 años vividos en aquellos lugares; el personaje Cortés se desdobla en el doble papel de protagonista (interpretado por un indio que representa una obra escrita por un marginal, Bernal Díaz del Castillo) y espectador (se mira a sí mismo en el escenario quince años después de los hechos representados). Pero, ¿qué cambia en la visión de los hechos a raíz de esta compleja estructura cubista? En esencia nada, pero bastante en la evaluación de los hechos, y es el Cortés que asiste a la representación el que se hace portavoz del Sender maduro y americanizado.
Igual es la conciencia de la parcialidad de quien escribe la Historia: en ambas obras Cortés invita al escribano a «dejar en el tintero» hechos no muy dignos de su empresa (Hernán Cortés, p. 84, Jubileo..., p. 108); esta idea está reforzada en Jubileo... al afirmar Cortés: «Voto al diablo que el que haya escrito este retablo es un hijo de puta que sabe poner las cosas como fueron» (p. 83) y «Ahora todo el mundo anda buscando el reverso de mi historia» (p. 135). Igual es la desconfianza en una justicia superior, invocada por Cortés primero en sus pleitos con don Diego Velázquez, y luego al recibir la noticia de la excomunión por su relación con la Malinche. Tampoco en este caso, como en Tupac Amaru y en La aventura..., el Rey, invocado como Poder lejano pero justiciero, responde a las justas espectativas de sus súbditos ni, como el rey lopesco, interviene como deus ex machina. Sender aquí expresa su desconfianza total en el Poder, y el rey de Jubileo... se revela aún más inepto e inerte frente al poder eclesiástico y burocrático, diciendo a Cortés: «alguaciles y escribanos son más necesarios al imperio que tú. Ellos conservan mis estados. Tú lo has aumentado, es verdad, pero el imperio existía antes y se podía pasar sin ellos, no $\sin$ los alguaciles y los escribanos [...] $\mathrm{La}$ Iglesia no puede pasar sin la disciplina eclesiástica y sin los sacerdotes. En cierto modo es lo mismo. La vida es así y no la vamos a cambiar nosotros» (Jubileo..., p. 36, pero también en Hernán Cortés, pp. 166-167). Igual es el desprecio hacia los representantes de la España oficial, don Diego Velázquez, don Pánfilo de Narvaez, padre Bartolomé ( «He tenido que pelear más recio contra alguaciles, escribanos y adelantados que contra los indios», Hernán Cortés, p. 167) pero también en este caso aumenta en Jublileo... la dosis de ironía y de desprecio («Hombres caían a su lado [de padre Bartolomé] pidiendo confesión, pero él bien corría», p. 166). Y aumen$\tan$ los rencores y los engaños en el campo español, y consecuentemente la actitud severa de Cortés hacia sus compañeros. Los personajes españoles en Jubileo... muestran su peor cara (por ejemplo Pedro de Alvarado que comentando una escena afirma: «Yo los odios a los mexicanos y no me importa cómo califican mi conducta", p. 198) lo que le sirve a Sender para subrayar, como confrontación, la actitud de Cortés, valiente y calculador, cre-
40 Ibid., p. 342.

41

A la connotación de representación que tienen todas las procesiones, podemos darle un valor añadido si pensamos en la falsedad que en la narrativa de Sender acompaña a menudo a los representantes oficiales de la Iglesia.

El nuevo descubrimiento de los exiliados españoles en América ROSA MARIA GRILLO 
yente $y$ anticlerical, hombre del Renacimiento que bien sabe manejarse entre intrigas $y$ falsedades y utilizarlas para sus fines, pero siempre respetuoso hacia lo 'otro'. Si estos caracteres eran ya evidentes en Hernán Cortés ( «cada país tiene sus usos», p. 82; «sentía cierto respecto por este hombre, fiel a los suyos», p. 92; «Un dios sabe morir [...] Debe morir. Sólo ahí se comprueba su divinidad. Pero no morir huyendo de la muerte, sino yendo a ella con alegría, como Xhinotecatl. El sí que era de casta de dioses», p. 149) se refuerzan notablemente en Jubileo... ( "Como hay Dios, que Xhinotecatl era un valiente y que daría algo por devolverle la vida», p. 135; «Cortés [...] no quiere destruir más casas, ni dar más batallas, ni derramar más sangre», p. 181). Una novedad consistente la constituye la Aparición - fraile y soldado, pagano y cristiano, Pólux y Santiago- que, dialogando antes con Cortés y luego con Huitxhilopotxtly, dios azteca de la guerra, exalta las virtudes humanas de Cortés: «tú peleabas sin odio y por eso les llevabas una gran ventaja. No quieres matar sino dispersar. No herir sino desbaratar [...] porque tú admiras a toda esta gente pobre y valerosa en el secreto de tu corazón y amas a todos ésos que por el martirio cumplieron su secreto designio» (Jubileo..., p. 175). Y más aún, si en Hernán Cortés los muertos tenían un papel muy limitado, y aparecían sólo en el último cuadro, en Jubileo... se amplía su presencia, quizás por un acercamiento a la cosmogonía indígena: desde el inicio de la representación ya están «en un extremo de la sala, bajo un rayo de luz que caía de una claraboya [...] con las caras muy blancas y las manos pintadas de rojo para diferenciarlos de los vivos» (p. 20); luego, en el capítulo XXIV, empiezan a actuar «varios soldados muertos» (p. 168).

Otros cambios apuntan a dar mayor visibilidad a Doña Marina, que en cuanto 'puente' entre las dos civilizaciones puede hacer comparaciones y emitir juicios ( Los malos se ríen sin alegría y en eso la gente de México es mejor que vosotros. Ellos no ríen sino cuando están contentos y como no lo están nunca...nunca ríen», Jubileo..., p. 185) y a dar mayor espacio a usos, costumbres y religiosidad indígenas (por ejemplo en la escena de la muerte de Moctezuma, pp. 158-161, y en el diálogo entre la Aparición y Huitxhilopotxtly, pp. 189-195).
La comparación entre las dos obras, además de demostrar un mayor dominio del espacio y de las técnicas teatrales por parte de Sender, nos hace ver su proceso de maduración tanto en relación con el tema específico de la Conquista como en la definición de sus personajes. Todas las novedades presentes en Jubileo... - y expresadas en mayor medida en el nivel 1 - tienden a criticar la esencia y las modalidades de la conquista española, la codicia, la crueldad y la inmoralidad de sus representantes, y al mismo tiempo a exaltar la dignidad, la religiosidad y la lealtad de los indios. ¿Qué papel han tenido en esta evolución el conocimiento directo de la realidad mexicana y la política franquista, con su reapropiación de la España imperial y católica, de aquella España que había destruido el imperio azteca y castigado a Cortés por rebelde a la autoridad eclesiástica e imperial? Sin duda los cambios que intervienen en Jubileo... dependen sobre todo del rechazo, por parte de Sender, del destino español en lo que tiene, aún en 1964, del destino imperialista y absolutista del 500, y de la asunción del destino americano: una vez más, el destino de los vencidos. Y no importa que Cortés esté en el panteón de los héroes españoles porque para Sender la verdad humana de Cortés está en el hombre que ha derrotado y honrado a Xhinotecatl, y que, a pesar de sus méritos de conquistador, ha sido marginado y rechazado por la burocracia civil, militar y religiosa. Por boca de la Aparición, Sender puede expresar su 'verdad' sobre Cortés: «tu gloria es sólo el reverso de tu miseria como son todas las glorias genuinas de guerra o de paz» (p. 201).

Las características tanto negativas como positivas de los protagonistas están más matizadas y al mismo tiempo se van radicalizando ya que al Sender maduro, más allá de ser partidario de un bando u otro, le interesan los hombres - Cortés y Xhinotecatl, pero también Moctezuma, la Malinche, Pedro de Alvarado, padre Bartolomé-, esas mezclas de impulsos contradictorios, de grandezas y miserias, esa capacidad de elevarse más arriba de su época y dejar en ella su propia huella que permite a un hombre ser recordado: «Los héroes no mueren. Alvarado, si volvemos a México y castigamos a esta nación y la destruimos o somos destruidos por ella tampoco nosotros moriremos. Tú no morirás, ni yo.
El nuevo descubrimiento de los ROSA MARIA GRILLO 
Tampoco tú morirás ya nunca, doña Marina» (Jubileo..., p. 172).

Además, en Jubileo..., Sender deja al lector la posibilidad de múltiples lecturas, lo que corresponde a uno de los aspectos que hemos indicado como característico de este nuevo 'descubrimiento' literario de América y de la narrativa histórica posmoderna: poner en discusión la versión oficial de la Historia y proponer lecturas alternativas $y$ hasta en contradicción entre sí. En este caso, tenemos la voz del Cortés de las Relaciones (contemporánea a los hechos y cercana a lo expresado en $\mathrm{Her}$ nán Cortés) y del Cortés que asiste a la representación del Zócalo, la voz de Bernal Díaz del Castillo que es señalado como el presunto autor del retablo y constituye la fuente preferida de Sender porque es 'sospechosa a los eruditos', las versiones populares de los romances y de las leyendas de raíz indígena, una posible versión de la Malinche, que habría recibido las confidencias del mismo Cortés y, en fin, una reinvención poética de los hechos. El
Cortés espectador, luego de reconocer la veracidad de lo representado, tiene las mismas dudas del lector: «¿Quién será el bellaco que lo ha escrito? ¿O han sido varios? Corchetes, escribanos, frailes y pajes. Ellos son los que suelen hacer la historia hablada» (p. 84). Una 'historia hablada' que puede contener más verdades que la Oficial, como nos ha enseñado la moderna historiografía.

A veces con tonos crispados y agudos, gritando su disconformidad hacia la Historia Oficial y utilizando técnicas escriturarias anti-realistas; otras en voz baja, insinuando en un tejido narrativo tradicional otras posibles verdades, los escritores españoles americanizados han 'quitado la cobertura', como diría Opoton, al Descubrimiento y al discurso historiográfico que lo ha narrado, poniéndose al paso, y quizás hasta anticipándose, al revisionismo de estas últimas décadas y a la narrativa posmoderna latinoamericana, que ha hecho del Descubrimiento y de la Conquista tema privilegiado de sus obras. 